\title{
An experimental study of hydrolytic behavior of thulium in basic and near-neutral solutions
}

\author{
S. A. Stepanchikova ${ }^{1}$, R. P. Biteykina ${ }^{1}$, A. A. Sava ${ }^{2}$ \\ ${ }^{1}$ Institute of Geology and Mineralogy, Siberian Division of Russian Academy of Sciences, Novosibirsk, Russia \\ ${ }^{2}$ Novapharm Ltd., Sydney, Australia \\ Email: step@igm.nsc.ru
}

Received 17 January 2013; revised 19 February 2013; accepted 25 February 2013

Copyright (C) 2013 S. A. Stepanchikova et al. This is an open access article distributed under the Creative Commons Attribution License, which permits unrestricted use, distribution, and reproduction in any medium, provided the original work is properly cited.

\begin{abstract}
Hydrolytic equilibria of Tm (III) in KOH solutions were studied at $25^{\circ} \mathrm{C}$. A spectrophotometry with $m$ cresol purple and 2-naphthol as $\mathrm{pH}$ indicators was used at an ionic strength of not more than 0.0005 . The results indicate that in freshly prepared solutions at $\mathrm{pH}$ ranging between 6 and $10 \mathrm{Tm}$ is presented as $\operatorname{Tm}^{3+}, \operatorname{Tm}(\mathrm{OH})^{2+}, \operatorname{Tm}(\mathrm{OH})_{2}^{+}$and $\operatorname{Tm}(\mathrm{OH})_{3}^{0}$. The stepwise stability constants of hydroxide complexes calculated at zero ionic strength were obtained as coefficient of linear regression equations from the graph of optical densities of the indicators in Tm solutions at varying $\mathrm{pH}$.
\end{abstract}

Keywords: Rare Earth Elements; Thulium; Stability Constants; Spectrophotometry; pH-Indicators

\section{INTRODUCTION}

Recently, the studies of rare earth elements (REE) complexing have been considerably intensified due to evaluating the fate of the REE compounds in the environment [1-3]. Producing and accumulating of significant quantities of REE during nuclear fission in uranium and Plutonium reactors are a potential source of their formation. The lanthanides complexes are among the most important compounds in natural waters regarding predominant anions [4]. According to the data of its abundance in the Earth's crust thulium appears to be the rarest among rare earth elements after promethium [5]. However, due to a potential risk of uptake by human bodies, animals and plants, further research in the chemistry of thulium complexes affecting the process of metabolism is needed. It has already been proven [6] that REE complexes could affect the ionic channels functioning and potentially lead to interrupting of the impulse transmission among the nerve cells.
According to the review of the published literature, thulium appears to be the least researched element amongst lanthanides due to an exclusively complex technology of its production and very high prices. The published experimental data on thulium hydrolytic behavior at $25^{\circ} \mathrm{C}$ are very limited, and being obtained under different experimental conditions, these are often incomparable with each other [7-10]. For example, in [7] the value of the stability constant of the $\mathrm{Tm}(\mathrm{OH})^{2+}$ monohydroxocomplex, assayed by potentio metric titration in the $\mathrm{Tm}_{2} \mathrm{O}_{3}$ solutions at the ionic strength of 0.3 , is reported as 5.78 log.unit The corresponding stability constant of the isotope ${ }^{170} \mathrm{Tm}$, assessed by chelating organic ligands extraction together with radio-chemical labelling, is 9.6 log.unit and differs by nearly 4 log.unit [8]. The submitted data demonstrate a dispersion typical for Tm hydroxoforms stability in aqueous solutions. Hydroxocomplexes of higher order usually are evaluated at considerable ionic strengths have very often, either not been identified, or the researchers anticipate presence of different complexes in similar experimental conditions. This could be considered as one of the major explanation for a great variability of the published data.

We studied hydrolythic equilibria in $\mathrm{Tm}^{3+}$ solutions with a possible participation of higher order hydroxoforms besides of $\operatorname{Tm}(\mathrm{OH})^{2+}$. To minimize the experimental errors caused by extrapolation to the zero ionic strength we studied hydrolytic reactions at minimal ionic strengths.

\section{MATERIALS AND METHODS}

Spectrophotometric $\mathrm{pH}$ measurement of the solutions containing variable $\mathrm{TmCl}_{3}$ concentrations and constant concentrations of the acid-alkaline indicators and $\mathrm{KOH}$ were carried out. An increase in Tm concentration resulted in a decrease of the absorption of the deprotonized form of the indicator due to an increase in the protons 
quantity as per following reaction:

$$
\mathrm{Tm}^{3+}+n \mathrm{H}_{2} \mathrm{O} \leftrightarrow \mathrm{Tm}(\mathrm{OH})_{n}^{3-n}+n \mathrm{H}^{+}
$$

The $\mathrm{pH}$ values were calculated from the measuring absorption densities of the indicator using tabulated values of the ionization constants [9]. The obtained values of ligand number $\boldsymbol{n}$ were used to calculate thermodynamic values of the formation constants of hydroxocomplexes. In the solutions containing $m$-cresol purple the measured $\mathrm{pH}$ values were between 6 and 8 and in 2-naphtol-containing solutions these were between 9 and 10 .

\section{CALCULATIONS}

Reactions of hydroxocomplexes formation in solutions of trivalent metal ions

$$
\mathrm{M}^{3+}+n \mathrm{OH}^{-} \leftrightarrow \mathrm{M}(\mathrm{OH})_{n}^{3-n}
$$

are characterized by stepwise ${ }^{\circ} K_{n}$ and total ${ }^{\circ} \beta_{n}$ stability constants expressed at zero ionic strength by the equations:

$$
\begin{gathered}
{ }^{o} K_{n}=\frac{\left[\mathrm{M}(\mathrm{OH})_{n}^{3-n}\right]}{\left[\mathrm{M}(\mathrm{OH})_{n-1}^{3-(n-1)}\right]\left[\mathrm{OH}^{-}\right]} \\
{ }^{o} \beta_{n}=\frac{\left[\mathrm{M}(\mathrm{OH})_{n}^{3-n}\right]}{\left[\mathrm{M}^{3+}\right]\left[\mathrm{OH}^{-}\right]^{n}}
\end{gathered}
$$

Both indicators are weak organic acids (HA) that react with a strong inorganic base $\mathrm{KOH}$ :

$$
\mathrm{HA}+\mathrm{OH}^{-} \leftrightarrow \mathrm{A}^{-}+\mathrm{H}_{2} \mathrm{O}
$$

where $\mathrm{HA}$ and $\mathrm{A}^{-}$are the protonated and deprotonated forms of the indicator, respectively.

If the equilibrium constant $K_{B H A}$ for reaction (5)

$$
K_{B H A}=\left[\mathrm{A}^{-}\right] /[\mathrm{HA}]\left[\mathrm{OH}^{-}\right]
$$

is known, the equilibrium concentrations $[\mathrm{HA}],\left[\mathrm{A}^{-}\right]$and consequently $\left[\mathrm{OH}^{-}\right]$and $\mathrm{pH}$ of the solution under study can be evaluated from the spectra.

The reaction between potassium hydroxide and the indicator (being a weak acid) neutralizes its HA part into KA salt (5). Then the solution denoted as number 1, containing the acid and $\mathrm{KOH}$ without $\mathrm{Tm}$, has buffering properties. Therefore, adding the increasing of protons concentration would be equivalent to titration of alkaliscent solutions by a strong acid. The protons would react with $\mathrm{A}^{-}$increasing the concentration of the weak acid HA. If the buffering capacity of the Tm-containing solutions is insufficient, the remainder of protons would neutralize $\mathrm{OH}^{-}$-ions in the solution (i). The equation for protons created in the hydrolytic reactions can be written as:

$$
\begin{aligned}
{\left[\mathrm{H}^{+}(\mathrm{i})\right]_{h y d r}=[} & \mathrm{HA}(\mathrm{i})]-[\mathrm{HA}(1)] \\
& +\left[\mathrm{OH}^{-}(1)\right]-\left[\mathrm{OH}^{-}(\mathrm{i})\right]
\end{aligned}
$$

If hydrolysis is treated as splitting off a proton from a water molecule in the hydrate shell of the rare earth ion, the number of produced protons would be equal to the number of hydroxide ions bound into complexes:

$$
\left[\mathrm{H}^{+}\right]_{h y d r}=\sum_{p=1}^{p=N} p \cdot\left[\operatorname{Tm}(\mathrm{OH})_{p}^{3-p}\right]
$$

and therefore the ligand number $\vec{n}$ can be calculated from Equation (9), where $C_{\mathrm{Tm}}$ is the analytical concentration of Tm. The index $i$ is omitted for simplicity in the Equations (8) and (9).

The calculation algorithm was based on the stepwise approach and consisted of the following stages:

1) The activity coefficients were initially assumed to be equal to 1 .

2) $\mathrm{HA}, \mathrm{A}^{-}$and consequently $\mathrm{OH}^{-}$equilibrium concentrations were calculated using optical densities.

3) $\boldsymbol{n}$ values were calculated using Equation (8).

4) ${ }^{o} K_{n}$ values were expressed from (9) and calculated as the linear lest square method parameters.

5) Concentration of hydroxocomplexes and activity coefficients were calculated using the values obtained. Activity coefficients were evaluated by the Debye-Hü ckel equation in the second approximation.

6) The program was returned to Step 2, until all the calculated values became constant according to the preset accuracy.

The complex forms $\mathrm{Tm}^{3+}, \mathrm{Tm}(\mathrm{OH})^{2+}$ and $\operatorname{Tm}(\mathrm{OH})_{2}^{+}$, interlinked by the constants ${ }^{o} K_{1}$ and ${ }^{o} K_{2}$, were assumed to be present in solutions containing $m$ cresol purple. They were calculated by the regressive equations:

$$
\frac{1-\vec{n}}{2-\vec{n}}=\frac{1}{{ }^{o} K_{1}} \cdot \frac{\vec{n}}{(2-\vec{n}) \cdot\left[\mathrm{OH}^{-}(i)\right]^{2} \cdot \gamma_{1}(i) \cdot \gamma_{3}(i)}-{ }^{o} K_{2}
$$

where $\gamma_{1}(i)$ and $\gamma_{1}(i)$ are the activity coefficients for uni- and trivalent ions.

$\mathrm{Tm}(\mathrm{OH})_{2}^{+} \operatorname{Tm}(\mathrm{OH})_{3}^{0}$ complexes were suggested in 2-naphthol-containing solutions within the measured $\mathrm{pH}$

$$
\vec{n}=\frac{\sum_{p=1}^{p=N} p \cdot\left[\operatorname{Tm}(\mathrm{OH})_{p}^{3-p}\right]}{C_{T m}}=\frac{\sum_{p=1}^{p=N} p \cdot\left[\operatorname{Tm}(\mathrm{OH})_{p}^{3-p}\right]}{\left[\operatorname{Tm}^{3+}\right]+\sum_{p=1}^{p=N}\left[\operatorname{Tm}(\mathrm{OH})_{n}^{3-p}\right]}
$$


interval. The stability constants ${ }^{o} K_{3}$ were evaluated as per following equation:

$$
\frac{\vec{n}-2}{3-\vec{n}}={ }^{o} K_{3} \cdot\left[\mathrm{OH}^{-}(i)\right] \cdot \gamma_{1}(i)^{2}
$$

\section{EXPERIMENT}

The absorption spectra of $\mathrm{pH}$-indicators solutions containing "analytical grade" $\mathrm{TmCl}_{3}$ (sourced from the Novosibirsk plant of chemical reagents) have been measured. The solutions for spectroscopy were prepared from $0.01 \mathrm{M} \mathrm{TmCl}_{3}$ aqueous stock solution with $\mathrm{pH} 5.84$. The Tm concentration was controlled spectroscopically with an arsenazo [11]. Concentration of $\mathrm{KOH}$ (analytical grade ALDRICH) was monitored by titration with $\mathrm{HCl}$. The indicators ("Indicator grade" ACROSS ORGANICS) were monitored by comparing of their extinctions with the corresponding values obtained from the reagent purified by vacuum sublimation and multiple crystallization [12]. Twice-distilled water boiled for longer than 2 hours was used.

The spectra of solutions were measured in closed quartz cells with $5 \mathrm{~cm}$ optical length using UV VIS spectrophotometer Specord M40. The experimental error was evaluated using the law of errors propagation. Its value depended on the accuracy of solution preparation and photometric measurement and did not exceed $1.2 \%$ at $25^{\circ} \mathrm{C}$. The accuracy of experimental evaluation of the stability constants was calculated as standard deviations of the linear regression parameters.

\section{RESULTS AND DISCUSSION}

\subsection{Measurements in Solutions of m-Cresol Purple}

The sulfonaphthalein indicator $m$-cresol purple $(m \mathrm{CP})$ was used by Clayton and Byrne for surface and deep-water spectrophotometric $\mathrm{pH}$ measurement of sea water [13]. According to the results it exists in three forms$\mathrm{H}_{2} \mathrm{I}, \mathrm{HI}^{-}$and $\mathrm{I}^{2-}$. In the visible range within the interval of the measured $\mathrm{pH}$ values $m \mathrm{CP}$ 's spectrum is represented by distinct intensive bands corresponding to its protonated $\left(\mathrm{HI}^{-}, v_{\max }=23,041 \mathrm{~cm}^{-1}\right)$ and deprotonated $\left(\mathrm{I}^{2-}, \quad v_{\max }=17,301 \mathrm{~cm}^{-1}, \varepsilon_{\max }=32,163\right)$ forms. According to our preliminary measurements, the extinction values of $\mathrm{HI}^{-}$were ranging from 0 to 408 within the 15,400 to $17,300 \mathrm{~cm}^{-1}$ interval. That allowed to disregard $\mathrm{HI}^{-}$absorption in our measuring of absorption of the $\mathrm{I}^{2-}$ band. This indicator was also used by the authors of [9] when studying a comparative hydrolythic behavior of REE.

The chemical equilibrium between two forms of $m \mathrm{CP}$ : $\mathrm{I}^{2-}+\mathrm{H}^{+} \leftrightarrow \mathrm{HI}^{-}$is described by stepwise formation constant:

$$
K_{a}=\frac{\left[\mathrm{HI}^{-}\right]}{\left[\mathrm{H}^{+}\right]\left[\mathrm{I}^{2-}\right]}
$$

The value of $\mathrm{p} K_{a}$ ionization at $25^{\circ} \mathrm{C}$ and an ionic strength 0.7 is equal to 8.146 according to [13]. We recalculated the values of $\mathrm{p} K_{a}$ for the zero ionic strength.

Figure 1 shows as an example the spectra of $m \mathrm{CP}$ vs $\mathrm{pH}$ in $\mathrm{KOH}$ and $\mathrm{TmCl}_{3}$ solutions. They are characterized by distinct isobestic point at $20,500 \mathrm{~cm}^{-1}$. The initial analytical concentrations of $\mathrm{KOH}$ and $m \mathrm{CP}$ in this experiment were constant and equal to $2.6 \times 10^{-4}$ and $3.9 \times$ $10^{-5}$, respectively. The concentration of $\mathrm{TmCl}_{3}$ in series of 10 solutions varied from 0.0 to $5.0 \times 10^{-5} \mathrm{M}$. The $\mathrm{pH}$ values were estimated as negative logarithm of hydrogen ions activity and were calculated by comparing of $\mathrm{I}^{2-}$ absorption in solutions under study (i) with the absorption in solution (0) with $\mathrm{KOH}$ concentration of $0.01 \mathrm{M}$, were all the indicator is in the $\mathrm{I}^{2-}$ form.

The published data confirms that $m \mathrm{CP}$ forms complexes with $\mathrm{Fe}$ (III) [14]. As for complex formation with $\mathrm{Tm}$ in our experiment: in this case the absorption of $\mathrm{I}^{2-}$ had to be decreased with increasing of metal concentration without any isobestic point. Should the Tm hydroxocomplexes be also formed, the isobestic point would be displaced vertically down. The pattern of spectra in Figure 1 demonstrates that under conditions of our experiment the only change in $\mathrm{pH}$ occurs due to the change of indicator forms but not of its concentration.

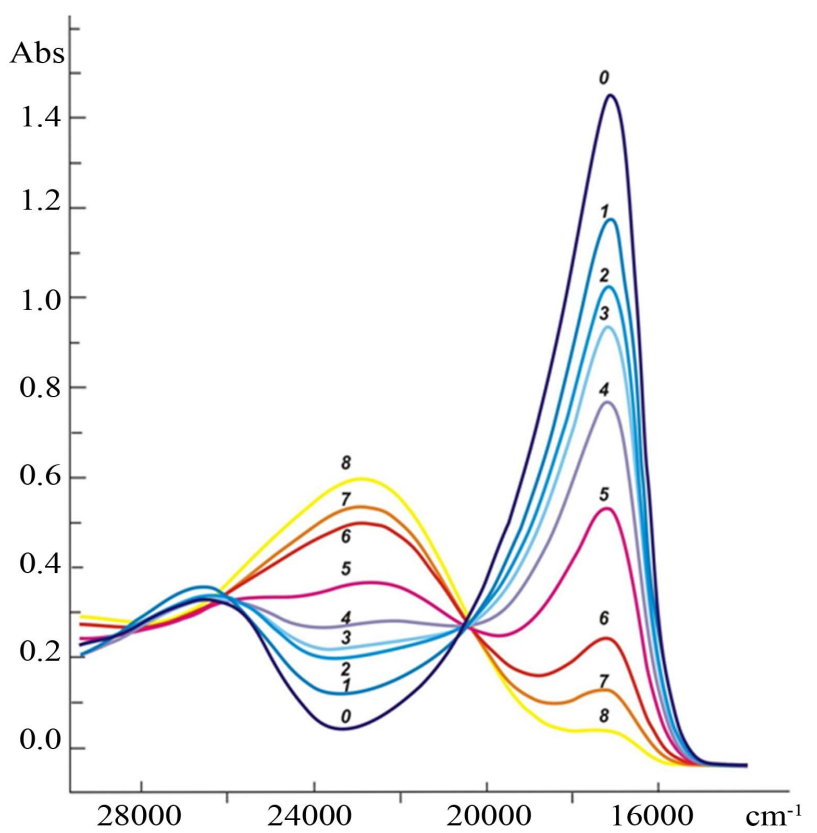

Figure 1. Effect of $\mathrm{TmCl}_{3}$ concentration (M) on spectra $\mathrm{m}$ cresol purple in $\mathrm{KOH}$ solutions; (0) 0.0 ; (1) 0.0 ; (2) $1.0 \times 10^{-5}$; (3) $1.5 \times 10^{-5}$; (4) $2.0 \times 10^{-5}$; (5) $2.5 \times 10^{-5}$; (6) $3.0 \times 10^{-5}$; (7) $3.5 \times 10^{-5}$; (8) $4.0 \times 10^{-5}$. Concentration of $\mathrm{KOH}$ in solution $(0)$ is $0.01 \mathrm{M}$. 
Table 1 shows the values of $\log ^{o} K_{1}$ and $\log ^{o} K_{2}$ averaged for 9 wave numbers within the studied 15,800 $17,300 \mathrm{~cm}^{-1}$ interval, and their standard deviations. Table 2 compares our experimental values of $\log ^{o} K_{1}$ with the published data. The experimental conditions differ considerably both from ours and among themselves. These are due to the different reagent concentration, measured $\mathrm{pH}$ values and the proposed forms of hydroxocomplexes present in the solutions within the studied $\mathrm{pH}$ range. This could explain the observed data disagreement.

Unfortunately, we could not find in literature the experimental data on the values of ${ }^{\circ} K_{2}$ for Tm. However these are available for erbium [15], where hydrolysis of Er by measuring of solubility of its freshly precipitated hydroxides was studied. The logarithmic values of stability constants for erbium solutions with concentrations up to $0.1 \mathrm{M}$ in the $1 \mathrm{M} \mathrm{NaClO}_{4}$ medium (under conditions excluding the presence of $\mathrm{CO}_{2}$ ) are as follows: $\log ^{o} \beta_{1}$ $=7.7, \log ^{o} \beta_{2}=13.5, \log ^{o} \beta_{3}=18.9, \log ^{o} \beta_{4}=19.2$. Taking into account the difference of experimental conditions one can consider that the value $\log ^{o} \beta_{2}=15.09$ for thulium which we have obtained at the zero ionic strength satisfactorily agrees with the results of [15].

\subsection{Measurements in Solutions of 2-Naphthol}

The ionization constant of 2-naphthol $K_{a}$ is determined by the equation:

$$
K_{a}=\frac{\left[\mathrm{NapO}^{-}\right] \cdot\left[\mathrm{H}^{+}\right]}{[\mathrm{NapOH}]}
$$

where $\mathrm{NapOH}$ and $\mathrm{NapO}^{-}$are the protonated and deprotonated forms of 2-naphthol, respectively. The values of $\mathrm{pK}_{\mathrm{a}}$ were defined spectrophotometrically up to $400^{\circ} \mathrm{C}$ in [16] and then used by the authors [17] for measuring equilibrium constants in solutions of sulfuric acid and ammonia, as well as boric acid [18] at elevated temperatures and pressure. According to [17], the value of $\mathrm{p}^{\circ} K_{\text {a }}$ at $25^{\circ} \mathrm{C}$ is 9.63 . Figure 2 presents the absorption spectra of 2-naphthol in solutions $\mathrm{KOH}$ and $\mathrm{TmCl}_{3}$ which depend upon $\mathrm{pH}$. The absorption band in the interval $26,000-30,000 \mathrm{~cm}^{-1}$ belongs to $\mathrm{NapO}^{-}$. Table 3 presents data for the averaged values of $\log ^{o} K_{3}$ and their standard deviations. The measurements were carried out in the range from 27,200 to $28,800 \mathrm{~cm}^{-1}$ in nine points of the spectra. The initial analytical concentration $\mathrm{KOH}$ and 2-naphthol were constant and equal to $3.0 \times 10^{-4}$ and 1.0 $\times 10^{-4} \mathrm{M}$ respectively. The $\mathrm{TmCl}_{3}$ concentration varied from $0.0 \mathrm{M}$ to $4.5 \times 10^{-5} \mathrm{M}$ in the series of 10 solutions. The $\beta_{3}$ values are published by Fatin-Rouge and Bünzliin [19]. The authors had determined the hydrolysis constant for a series of rare earths elements by potentiometeric titration of $0.002 \mathrm{M}$ solution $\mathrm{Ln}\left(\mathrm{ClO}_{4}\right)_{3}$ at a constant ionic strength supported by the adding $0.1 \mathrm{M} \mathrm{NaCl}$. However, only complex forms $\mathrm{Tm}^{3+}$ and $\mathrm{Tm}(\mathrm{OH})_{3}^{0}$ were suggested within $\mathrm{pH}$ range of $8.5-11$. The measured value of ${ }^{*} \beta_{3}-21.14$ could be considered as agreeing with our results (19.35) if the difference in the experimental conditions is accounted for.

\section{CONCLUSIONS}

The number of bound hydroxide ions as well as thermodynamic values of the stability constants of the first three

Table 1. Experimental data for calculations of $\log ^{o} K_{n}$ and their standard deviations (sd) in solutions of $m$-cresol purple measured at $v$ $=16,400 \mathrm{~cm}^{-1}$.

\begin{tabular}{|c|c|c|c|c|c|c|}
\hline $\begin{array}{c}\text { No. } \\
\text { solutions }\end{array}$ & $C_{\mathrm{Tm}}$ & Optical density & pH calc. & $n$ calc. & \multicolumn{2}{|c|}{$\log ^{o} K_{n}$} \\
\hline 0 & 0.0 & 0.6868 & & & & \\
\hline 1 & 0.0 & 0.6047 & 7.890 & 0.00 & $\log { }^{0} \bar{K}_{1}$ & 8.58 \\
\hline 2 & 0.000010 & 0.5754 & 7.735 & 1.03 & sd $\log { }^{0} \bar{K}_{1}$ & 0.07 \\
\hline 3 & 0.000015 & 0.5406 & 7.589 & 1.06 & $\log { }^{0} \bar{K}_{2}$ & 6.52 \\
\hline 4 & 0.000020 & 0.5050 & 7.464 & 1.04 & sd $\log { }^{0} \bar{K}_{2}$ & 0.26 \\
\hline 5 & 0.000025 & 0.4132 & 7.199 & 1.06 & & \\
\hline 6 & 0.000030 & 0.3301 & 6.986 & 1.02 & & \\
\hline 7 & 0.000035 & 0.2222 & 6.698 & 0.96 & & \\
\hline 8 & 0.000040 & 0.1442 & 6.442 & 0.88 & & \\
\hline 9 & 0.000045 & 0.0576 & 5.978 & 0.79 & & \\
\hline 10 & 0.000050 & 0.0372 & 5.773 & 0.71 & & \\
\hline
\end{tabular}


Table 2. Comparison of the first hydrolysis constant of thulium at $25^{\circ} \mathrm{C}$ from literature data and those obtained in this work.

\begin{tabular}{|c|c|c|c|c|c|}
\hline Reference & Method & $I$ in $\mathrm{M}$, max. & $C_{\mathrm{Tm}}, \max$ & $\begin{array}{c}\text { Interval of } \\
\text { measured } \mathrm{pH}\end{array}$ & $\log ^{o} K_{1}$ \\
\hline $\begin{array}{l}\text { [4] Frolova and } \\
\text { Kumok, } 1966\end{array}$ & potentiometry & 0.3 & $9 \times 10^{-3}$ & $\sim(5-6)$ & 5.78 \\
\hline $\begin{array}{l}\text { [5] Guillaumont } \\
\text { et al., } 1971\end{array}$ & $\begin{array}{l}\text { extraction; } \\
\text { radiochemical } \\
\text { measurements }\end{array}$ & 0.1 & $\sim 10^{-7}$ & $\sim(2-8.5)$ & 9.60 \\
\hline $\begin{array}{l}\text { [3] Klungness and } \\
\text { Byrne, } 2000\end{array}$ & $\begin{array}{l}\text { potentiometry; } \\
\text { spectrophotometry }\end{array}$ & 0.7 & 0.01 & $\sim(4-10)$ & 6.61 \\
\hline This work & $\begin{array}{l}\text { spectrophotometry } \\
\text { using } \mathrm{pH} \text {-indicators }\end{array}$ & $5 \times 10^{-4}$ & $5 \times 10^{-5}$ & $6-8$ & 8.58 \\
\hline
\end{tabular}

Table 3. Experimental data for calculations of $\log ^{o} K_{n}$ and their standard deviations (sd) in solutions of 2-naphthol measured at $v=$ $27,600 \mathrm{~cm}^{-1}$.

\begin{tabular}{|c|c|c|c|c|c|c|}
\hline $\begin{array}{c}\text { No. } \\
\text { solution }\end{array}$ & $C_{\mathrm{Tm}}$ & Optical density & $\mathrm{pH}$ calc. & $n$ calc. & \multicolumn{2}{|c|}{$\log ^{o} K_{n}$} \\
\hline & & & & & & \\
\hline 1 & 0.0 & 0.5189 & 9.908 & 0.00 & $\log { }^{0} \bar{K}_{3}$ & 4.26 \\
\hline 2 & 0.000005 & 0.4791 & 9.815 & 4.67 & sd $\log { }^{0} \bar{K}_{3}$ & 0.25 \\
\hline 3 & 0.000010 & 0.4663 & 9.786 & 3.20 & & \\
\hline 4 & 0.000015 & 0.4470 & 9.743 & 2.84 & & \\
\hline 5 & 0.000020 & 0.4093 & 9.647 & 2.93 & & \\
\hline 6 & 0.000025 & 0.3868 & 9.597 & 2.73 & & \\
\hline 7 & 0.000030 & 0.3705 & 9.576 & 2.51 & & \\
\hline 8 & 0.000035 & 0.3330 & 9.493 & 2.49 & & \\
\hline 9 & 0.000040 & 0.2971 & 9.411 & 2.43 & & \\
\hline 10 & 0.000045 & 0.2811 & 9.374 & 2.27 & & \\
\hline
\end{tabular}

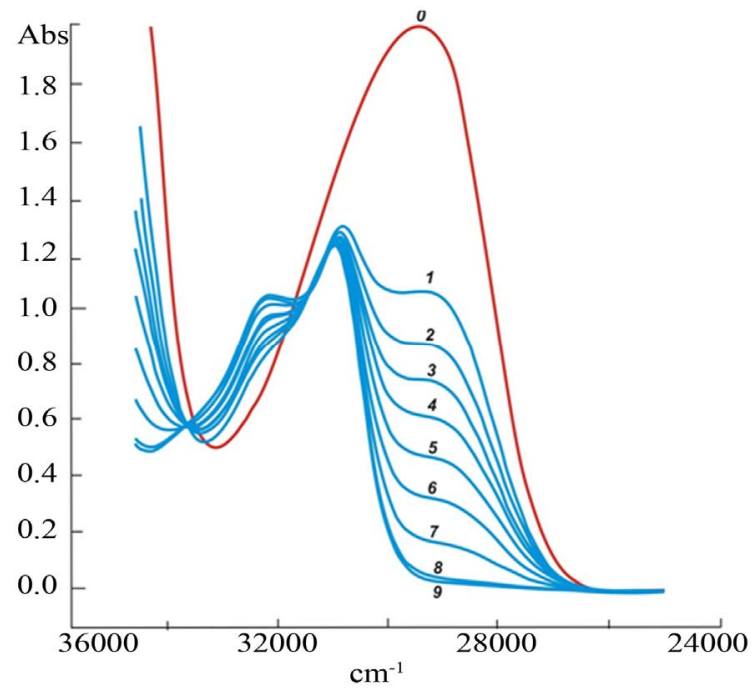

Figure 2. Effect of $\mathrm{TmCl}_{3}$ concentration (M) on spectra 2-naphthol in $\mathrm{KOH}$ solutions: (0) 0.0 ; (1) 0.0 ; (2) $5 \times 10^{-6}$; (3) $1.0 \times 10^{-5}$; (4) $1.5 \times 10^{-5}$; (5) $2.0 \times 10^{-5}$; (6) $2.5 \times$ $10^{-5}$; (7) $3.0 \times 10^{-5}$; (8) $3.5 \times 10^{-5}$; (9) $4.0 \times 10^{-5}$.

Tm (III) hydroxo complexes have been evaluated by the indicator spectrophotometric method in the absence of polymer forms, side reactions and hydroxides precipitate at $25^{\circ} \mathrm{C}$ at minimal ionic strength. Although the research was initially intended to form a basis for estimating stability of hydroxide, carbonic and mixed hydroxocarbonate forms of REE at elevated temperatures, the employed methodology at near-room temperatures has proved to be advantageous over the direct potentiometeric measurements Our methodology utilizes tabulated values of ionization constants and extinction coefficients of $\mathrm{pH}$ indicators that removes the need for electrode calibration during each measurement. The employed spectroscopic technique allows carry out direct observations of the hydrolythic behavior of elements in solutions.

The work was supported by the Russian Branch for Basic Research, project No. 11-05-00662-a.

\section{REFERENCES}

[1] Powell, K.J., Brown, P.L., Byrne, R.H., Gajda, T., Hefter, G., Leuz, A.-K., Sjöberg, S. and Wanner, H. (2011) Chemical speciation of environmentally significant metals with inorganic ligands. Part 4: The $\mathrm{Cd}^{2++} \mathrm{OH}^{-}, \mathrm{Cl}^{-}$, $\mathrm{CO}_{3}^{2-} \quad \mathrm{SO}_{4}^{2-}$, and $\mathrm{PO}_{4}^{3-}$ systems (IUPAC Technical 
Report). Pure and Applied Chemistry, 5, 1163-1214. doi:10.1351/PAC-REP-10-08-09

[2] Powell, K.J., Brown, P.L., Byrne, R.H., Gajda, T., Hefter, G., Leuz, A., Sjöberg, S. and Wanner, H. (2009) Chemical speciation of environmentally significant metals with inorganic ligands. Part 4: The $\mathrm{Pb}^{2++} \mathrm{OH}^{-}, \mathrm{Cl}^{-}, \mathrm{CO}_{3}^{2-}$, $\mathrm{SO}_{4}^{2-}$, and $\mathrm{PO}_{4}^{3-}$ systems (IUPAC Technical Report). Pure and Applied Chemistry, 12, 2425-2476. doi:10.1351/PAC-REP-09-03-05

[3] Wood, S.A. (2010) Advances in the aqueous solutions chemistry of trivalent rare earth elements at temoeratures up to $250^{\circ} \mathrm{C}$ : Relevance to near-field radioactive waste disposal environments. GSA Denver Annual Meeting, Geological Society of America Abstracts with Programs, 31 October-3 November 2010, 5, 357.

[4] Dubinin, A.V. (2006) Geochemistry of rare earth elements in the ocean. Nauka, Moscow.

[5] Riabchikov, D.I. and Riabouhin, V.A. (1966) Analytical chemistry of rare earth elements and yttrium. Nauka, Moscow.

[6] Ganjali, M.R., Norouzi. P. and Adergania, B.A. (2007) Thulium (III) ions monitoring by a novel thulium (III) microelectrode based on a S-N schiff base. Electroanalysis, 19, 1145-1151. doi:10.1002/elan.200603833

[7] Frolova, U.K., Kumok, V.N. and Serebrennikov, V.V. (1966) Hydrolisis of rare earth elements and yttrium in water solutions. Izvestia Visshih Uchebnih Zavedenij SSSR. Khimija I Khimitcheskaja Tekhnologija, 2, 176179.

[8] Guillaumont, R., Desire, B. and Galin, M. (1971) Premiere constante d'hydrolise des lanthanides. Radiochemical and Radioanalytical Letters, 3, 189-197.

[9] Klungness, G.D. and Byrne, R.H. (2000) Comparative hydrolysis behavior of the rare earth and yttrium: The influence of temperature and ionic strength. Polyhedron, 19, 99-107. doi:10.1016/S0277-5387(99)00332-0

[10] Baes, C.F. and Mesmer, R.E. (1976) The hydrolysis of cations. John Wiley, New York.
[11] Marchenko, Z.I. (1971) Photometric definitions of elements. Mir, Moscow.

[12] Soumillion, J.Ph., Vandereecken, P., Van Der Auweraer, M. and De Schryver, F.C. (1989) Photophysical analysis of ion pairing of $\beta$-naphtholate in medium polarity solvents: Mixtures of contact and solvent-separated ion pairs. Journal of American Chemical Society, 111, 2217-2225. doi:10.1021/ja00188a041

[13] Clayton, T.D. and Byrne, R.H. (1993) Spectrophotometric seawater $\mathrm{pH}$ measurement: Total hydrogen ion concentration scale calibration of $m$-cresol purple and atsea results. Deep-Sea Research, 40, 2115-2129. doi:10.1016/0967-0637(93)90048-8

[14] Chamjangali, M.A., Ghadamali, B. and Salek-Gilani, N. (2009) New induction period based spectrophotometric method for the determination of iron (II) in pharmaceutical products. Acta Chimica Slovakia, 50, 434-440.

[15] Kragten, J. and Decnop-Weever, L.G. (1983) Hydroxide complexes of lanthanides-V*. Erbium in perchlorate medium. Talanta, 2, 131-133. doi:10.1016/0039-9140(83)80033-2

[16] Xiang, T. and Johnston, K.P. (1994) Acid-base behavior of organic compounds in supercritical water. Journal of Physical Chemistry, 98, 7915-7922. doi: $10.1021 / \mathrm{j} 100083 \mathrm{a} 027$

[17] Xiang, T., Johnston, K.P., Wofford, W.T. and Gloyna, E.F. (1996) Spectroscopic measurement of $\mathrm{pH}$ in aqueous sulfuric acid and ammonia from sub- to supercritical conditions. Industrial Engineering Chemistry Researches, 35, 4788-4795. doi:10.1021/ie960368y

[18] Wofford, W.T., Gloyna, E.F. and Johnston, K.P. (1998) Boric acid equilibria in near-critical and supercritical water. Industrial Engineering Chemistry Researches, 37, 2045-2051. doi:10.1021/ie9707634

[19] Fatin-Rouge, N. and Bünzli, J.-C.G. (1999) Thermodynamic and structural study of inclusion complexes between trivalent lanthanide ions and native cyclodextrins. Inorganica Chimica Acta, 293, 53-60. doi:10.1016/S0020-1693(99)00227-3 